\title{
REATIVIDADE DE CORRETIVOS DA ACIDEZ E CONDICIONADORES DE SOLO EM COLUNAS DE LIXIVIAÇÃO ${ }^{(1)}$
}

\author{
Lucélia Alves Ramos ${ }^{(2)}$, Antonio Nolla ${ }^{(3)}$, Gaspar Henrique \\ Korndörfer $^{(4)}$, Hamilton Seron Pereira ${ }^{(5)}$ \& Monica \\ Sartori de Camargo ${ }^{(6)}$
}

\begin{abstract}
RESUMO
A acidez do solo é um dos principais fatores limitantes na produção agrícola. O calcário é o corretivo mais utilizado, porém tem lenta mobilidade no perfil do solo, sendo lenta a correção além da camada de incorporação. Por isso, outros produtos têm sido testados para a correção da acidez, como os silicatos, ou para a amenização de seus efeitos em camadas de solo mais profundas, como o gesso. Este trabalho teve como objetivo comparar o efeito do calcário, gesso e silicatos quanto à sua capacidade de fornecer $\mathrm{Ca}, \mathrm{Mg}$, $\mathrm{Si}$ e corrigir o $\mathrm{pH}$ do solo em profundidade. Foram utilizadas amostras de um Neossolo Quartzarênico Órtico típico coletado sob mata natural com baixos teores de Ca e Mg trocáveis e acidez elevada. Foram montados lisímetros, divididos em 12 anéis de $5 \mathrm{~cm}$, que foram preenchidos pelo solo amostrado, incorporando-se, no primeiro anel $(0-5 \mathrm{~cm})$, o equivalente a 500 e $1.000 \mathrm{~kg} \mathrm{ha}^{-1} \mathrm{de} \mathrm{Ca}$, na forma de silicato de cálcio (Wollastonita), silicato de Ca e Mg, termofosfato, calcário comercial (calcítico) e gesso agrícola, num delineamento em blocos casualizados com quatro repetições. As colunas de solo foram incubadas por quarenta dias, aplicando-se o equivalente a $2.000 \mathrm{~mm}$ de água destilada (cinco vezes/semana) durante os quarenta dias de incubação. Determinaram-se o $\mathrm{pH} \mathrm{CaCl}$, Ca e Mg trocáveis e Si disponível. O gesso aumentou os teores de Ca em todo o perfil do solo, mas não corrigiu a acidez. Os silicatos corrigiram a acidez do solo e aumentaram os teores de Ca trocável com maior
\end{abstract}

\footnotetext{
(1) Recebido para publicação em janeiro de 2005 e aprovado em julho de 2006.

(2) Engenheiro-Agrônomo, Mestrando em agronomia - GPSi/ICIAG, Universidade Federal de Uberlândia - UFU. Caixa Postal 593, CEP 38400-902 Umuarama, Uberlândia (MG). E-mail: luceliaar@hotmail.com

(3) Engenheiro-Agrônomo, Pós-Doutorando em Solos, GPSi/ICIAG/UFU. Bolsista do CNPq. E-mail: nolla73@hotmail.com

(4) Professor Titular do núcleo de Solos, UFU. Bolsista do CNPq. E-mail: ghk@triang.com.br

(5) Professor da Universidade Federal de Goiás - UFG. Campus Avançado de Jataí, Rodovia BR 364, km 192 CEP $75800-000$ Jataí (GO). E-mail: hsp@jatai.ufg.br

(6) Professor da Universidade Estadual de Goiás - UEG. Campus São Luís dos Montes Belos, Rua da Saudade 56, CEP 76100-000 Vila Eduarda - São Luiz de Montes Belos (GO). E-mail: mscamarg@yahoo.com.br
} 
eficiência que o calcário. A aplicação de silicato de Ca e Mg e de termofosfato aumentou a concentração de $\mathrm{Mg}$ no solo até à profundidade de $25 \mathrm{~cm}$. O Si foi carreado até às camadas mais profundas dos lisímetros $(55 \mathrm{~cm})$, independentemente da fonte de Si utilizada.

Termos de indexação: acidez do solo, Si, gesso agrícola, silicatos, calcário.

\title{
SUMMARY: REACTIVITY OF SOIL ACIDITY CORRECTIVES AND CONDITIONERS IN LYSIMETERS
}

\begin{abstract}
Soil acidity is one of the chief factors of constraint on agricultural production. Lime is the most used corrective, but, apart from the incorporation layer, of slow mobility and slow correction in the soil profile. Other products have been tested for acidity correction such as silicates or the reduction of acidity effects in deeper soil layers with gypsum. This study compared the effect of lime, gypsum and silicates to supply calcium, magnesium, silicate and to correct soil $\mathrm{pH}$ in deeper soil layers. Soil samples of an Ustoxic Quartzipsamment were used, collected under native forest, with low levels of exchangeable Ca and $\mathrm{Mg}$ and high acidity. Lysimeters were prepared, divided into 12 rings of $5 \mathrm{~cm}$ and filled with the collected soil. In the top ring $(0-5 \mathrm{~cm})$ the equivalent to 500 or $1.000 \mathrm{~kg} \mathrm{ha}^{-1}$ calcium silicate (Wollastonite), $\mathrm{Ca}$ and $\mathrm{Mg}$ silicate, thermophosphate, commercial (calcitic) lime, and agricultural gypsum were incorporated, in a randomized block design with 4 replications. The soil columns were incubated (moisture near field capacity) for 40 days, irrigated with $2.000 \mathrm{~mm}$ distilled water (five times/week) during the incubation period. Available silicon, exchangeable $\mathrm{Ca}$ and $\mathrm{Mg}$ and $\mathrm{pH}\left(\mathrm{CaCl}_{2}\right)$ were determined. Gypsum increased Ca levels throughout the soil profile, but did not correct the acidity. Silicates did correct soil acidity and were more effective than lime for soil $\mathrm{pH}$ correction and to increase exchangeable Ca levels. Use of calcium and magnesium silicate or of thermophosphate increased the soil magnesium concentration to a depth of $25 \mathrm{~cm}$. The measured Silicon was transported to the deepest soil layer in the lysimeters $(55 \mathrm{~cm})$, independently of the tested Si source.
\end{abstract}

Index terms: soil acidity, sub-surface, silicon, agricultural gypsum, silicates, lime.

\section{INTRODUÇÃO}

A acidez do solo é um dos principais fatores capazes de reduzir o potencial produtivo dos solos tropicais. Segundo Sousa \& Lobato (2004), grande parte dos solos de cerrado apresentam $\mathrm{pH}-\mathrm{H}_{2} \mathrm{O}$ baixo $(<5,5)$, alta concentração de $\mathrm{Al}^{3+}$ e baixos teores de $\mathrm{Ca}^{2+} \mathrm{e} \mathrm{Mg}^{2+}$, abrangendo a camada superficial $(0-20 \mathrm{~cm})$ e subsuperficial $(>20 \mathrm{~cm})$. A correção de todo o perfil de solo se faz necessária para que o sistema radicular das culturas explore maior volume de solo, de modo que a planta absorva água e nutrientes para seu crescimento e desenvolvimento (Nolla, 2004). Para tal, é efetuada a aplicação de substâncias, capazes de neutralizar prótons da solução do solo. Os materiais empregados como corretivo de acidez são basicamente os óxidos, hidróxidos, silicatos e carbonatos (Alcarde, 1992).

O calcário é o material mais utilizado; entretanto, para ser efetivo, requer água para sua dissolução, devendo ser incorporado ao solo para uma maior eficácia (Alcarde \& Rodella, 2003). Ele é capaz de neutralizar a acidez do solo e fornecer nutrientes, principalmente $\mathrm{Ca}$ e $\mathrm{Mg}$, porém, grande parte da ação do calcário fica restrita à camada de $0-20 \mathrm{~cm}$ (Rheinheimer et al., 2000; Amaral \& Anghinoni, 2001). No sistema plantio direto, onde geralmente a aplicação de calcário é feita na superfície do solo, a ação efetiva do calcário ocorre na camada de 0-10 cm (Sá, 1993, Amaral et al., 2004), se não houver íons, como nitrato, ou moléculas orgânicas carreadoras originadas de adubos verdes (Pavan, 1994 e 1998; Franchini et al., 1999), razão pela qual o sistema radicular da maioria das culturas irá predominar apenas na camada superficial do solo (Amaral et al., 2004). Isso pode ocasionar redução na produtividade das culturas, uma vez que nos solos de cerrado é freqüente a ocorrência de veranicos, os quais ocasionam baixa disponibilidade de água na camada superficial $(0-20 \mathrm{~cm})$.

Por esse motivo, tem sido utilizado o gesso $\left(\mathrm{CaSO}_{4} \cdot 2 \mathrm{H}_{2} \mathrm{O}\right)$, produto condicionador de solo, que apresenta alta mobilidade no perfil, capaz de disponibilizar os íons $\mathrm{Ca}^{2-}$ e $\mathrm{SO}_{4}{ }^{2-}$ em solução e de ser lixiviado, enriquecendo de nutrientes as camadas subsuperficiais e reduzindo a saturação por $\mathrm{Al}^{3+} \mathrm{em}$ profundidade (Alcarde \& Rodella, 2003). 
O termofosfato magnesiano, além de fertilizar o solo com $\mathrm{P}$, tem efeito corretivo, graça à sua reação alcalina (pH 8,0), que reduz as concentrações de $\mathrm{Al}$ e Mn no solo (Korndörfer \& Gascho, 1999; Korndörfer et al., 2004a; Vitti et al., 2004). Aliado ao efeito corretivo e fertilizante, ele apresenta, também, Si em sua composição, o que pode contribuir para o controle de pragas e doenças e aumentar a tolerância ao estresse hídrico (Korndörfer et al., 2004b).

Alguns resíduos siderúrgicos, subprodutos da fabricação do ferro (Coelho, 1998), também podem ser usados na correção da acidez do solo, constituindo uma alternativa para o aproveitamento de parte desses subprodutos acumulados pelas indústrias. Sua aplicação ao solo pode liberar Ca e, ou, $\mathrm{Mg}$ em solução e ânions $\left(\mathrm{SiO}_{3}{ }^{2-}\right)$ (Nolla, 2004). O mecanismo de correção da acidez pela escória resulta na formação de $\mathrm{SiO}_{3}{ }^{2-}$, que reage com a água e libera íons $\mathrm{OH}^{-}$, que neutralizam o $\mathrm{Al}^{3+}$ fitotóxico, conforme observado na equação descrita por Alcarde \& Rodella (2003):

$$
\begin{array}{lll}
\mathrm{CaSiO}_{3} & \rightarrow & \mathrm{Ca}^{2+}+\mathrm{SiO}_{3}{ }^{2-} \\
\mathrm{SiO}_{3}{ }^{2-}+\mathrm{H}_{2} \mathrm{O}_{\text {(solo) }} & \rightarrow & \mathrm{HSiO}_{3}{ }^{-}+\mathrm{OH}^{-} \\
\mathrm{HSiO}_{3}{ }^{-}+\mathrm{H}_{2} \mathrm{O}_{\text {(solo) }} & \rightarrow & \mathrm{H}_{2} \mathrm{SiO}_{3}+\mathrm{OH}^{-} \\
\mathrm{H}_{2} \mathrm{SiO}_{3}+\mathrm{H}_{2} \mathrm{O}_{\text {(solo) }} & \rightarrow & \mathrm{H}_{4} \mathrm{SiO}_{4}
\end{array}
$$

Segundo Alcarde \& Rodella (2003), o silicato de Ca é 6,78 vezes mais solúvel que o carbonato de $\mathrm{Ca}$ $\left(\mathrm{CaCO}_{3}=0,014 \mathrm{~g} \mathrm{~L}^{-1}\right.$ e $\left.\mathrm{CaSiO}_{3}=0,095 \mathrm{~g} \mathrm{~L}^{-1}\right)$, apresentando, portanto, um maior potencial para a correção da acidez do solo em profundidade que o calcário.

Vários trabalhos têm sido realizados para testar a eficiência dos silicatos na correção da acidez em subsuperfície. Pereira (1978) observou que a escória apresentou o mesmo poder corretivo que os calcários de diferentes origens em dois Latossolos. Veloso et al. (1992), no entanto, observaram que o calcário calcinado foi o produto que aumentou mais rapidamente o $\mathrm{pH}$ do solo, seguido do calcário dolomítico e da escória. Estudos realizados por Louzada (1987) indicaram que as escórias são um pouco menos eficientes na elevação do $\mathrm{pH}$ do solo que o calcário, sendo essas diferenças atribuídas ao valor neutralizante mais baixo da escória $(\mathrm{VN}=86 \%)$ comparado ao do calcário ( $\mathrm{VN}=100 \%)$.

Dalto (2003), estudando a correção da acidez do solo em profundidade pelo calcário e silicato de Ca e $\mathrm{Mg}$, em condições de campo, observou que, no primeiro ano, o calcário apresentou maior reatividade em relação ao silicato, para uma mesma dose aplicada. Isso pode estar relacionado com o menor PRNT (89\%) apresentado pelo silicato utilizado e com o tempo de contato entre a escória aplicada e o solo (Novais et al., 1993). Essa reação mais lenta do silicato pode ser influenciada pela presença de impurezas (como Al), que reduzem a solubilidade da escória (Ando et al., 1998), ou pela formação de uma película alcalina de óxidróxido de $\mathrm{Fe}$ e $\mathrm{Al}$ ao redor das partículas do corretivo no momento da hidrólise (Gomes, 1996).

De modo geral, a capacidade corretiva da acidez do solo das escórias é semelhante à do calcário. Entretanto, esses dois tipos de corretivos diferem quanto à superfície específica (área de contato) e quanto ao poder de neutralização (PN). O poder corretivo das escórias pode ser superior à do calcário, conforme a maior superfície específica de suas partículas. Quando se aplicam calcário e escória com granulometrias semelhantes (mesma reatividade - Re), no entanto, as escórias são menos eficientes na elevação do $\mathrm{pH}$ do solo. Essas pequenas diferenças de eficiência são atribuídas ao valor neutralizante mais baixo da escória (Louzada, 1987; Prado et al., 2001). Assim, pode-se inferir que seu uso proporciona o melhor aproveitamento de nutrientes pelas culturas semiperenes, como a cana-de-açúcar, e as perenes, cujo sistema radicular permanece por longo tempo explorando praticamente a mesma região do solo.

O trabalho foi desenvolvido em colunas de lixiviação (lisímetros) com o objetivo de observar a capacidade do calcário, do gesso e de silicatos em fornecer $\mathrm{Ca}$, $\mathrm{Mg}, \mathrm{Si}$ e corrigir o $\mathrm{pH}$ do solo em profundidade.

\section{MATERIAL E MÉTODOS}

Foram utilizadas amostras de um Neossolo Quartzarênico órtico típico (Embrapa, 1999a), localizado no município de Santa Vitória - MG, coletadas em condições de mata natural (Quadro 1). Esse solo foi selecionado de acordo com a baixa concentração de Ca e Mg trocáveis e com a elevada saturação por $\mathrm{Al}^{3+}(\mathrm{m}=71 \%)$. Dessa forma, foi possível estabelecer uma comparação entre materiais corretivos e condicionadores do solo, quanto à correção de acidez e disponibilidade de nutrientes no perfil do solo.

O experimento foi instalado em casa de vegetação da Universidade Federal de Uberlândia. Utilizaramse lisímetros com $10 \mathrm{~cm}$ de diâmetro x $60 \mathrm{~cm}$ de altura, divididos em 12 anéis de $5 \mathrm{~cm}$, revestidos internamente com sacos plásticos para evitar a perda de água e terra entre os anéis. Na parte inferior externa, foi colocada uma tela para evitar a perda de terra.

Os lisímetros foram preenchidos com terra fina seca ao ar (TFSA), moída e passada em peneira com malha de $2 \mathrm{~mm}$ de diâmetro, incorporando-se no primeiro anel $(0-5 \mathrm{~cm})$ dos lisímetros o equivalente a 500 e $1.000 \mathrm{~kg} \mathrm{ha}^{-1}$ de $\mathrm{Ca}$, provenientes dos tratamentos: gesso agrícola, silicato de Cálcio (Wollastonita), silicato de $\mathrm{Ca}$ e $\mathrm{Mg}$ (Recmix), termofosfato (Yorin), calcário comercial (calcítico), além do tratamento-testemunha, num delineamento em blocos casualizados, com quatro repetições (Quadros 2 e 3). 
As colunas foram incubadas por 40 dias, mantendose a umidade do solo próxima à capacidade de campo, aplicando-se o equivalente a $2.000 \mathrm{~mm}$ de água destilada (cinco vezes / semana), durante o período de incubação. Os lisímetros foram desmontados, separando-se a terra de cada anel, que foi seca ao ar, moída e passada em peneiras com malha de $2 \mathrm{~mm}$ de diâmetro. Determinou-se o $\mathrm{pH}$ em $\mathrm{CaCl}_{2}$ (relação 1:2,5 $-\mathrm{CaCl}_{2}$ 0,01 mol L-1); Ca e Mg trocáveis ( $\left.\mathrm{KCl} 1 \mathrm{~mol} \mathrm{~L}^{-1}\right)$, por espectrofotômetro de absorção atômica (Embrapa, 1999b), e Si disponível (extrator ácido acético 0,5 mol L-1 - Korndörfer, 2004a).

Os resultados foram submetidos à análise de variância, considerando o delineamento em blocos casualizados. Realizou-se a comparação de médias, usando o teste de Tukey, por meio do qual se obteve a diferença mínima significativa (DMS) a $5 \%$ de probabilidade de erro.

\section{RESULTADOS E DISCUSSÃO}

Os maiores teores de Ca trocável no solo ocorreram nas parcelas em que foi aplicada a dose de $1.000 \mathrm{~kg} \mathrm{ha}^{-1}$ dos materiais (Figura 1b), em relação à menor dose aplicada (500 kg ha-1 - Figura 1a). Na camada de 0 $5 \mathrm{~cm}$, as fontes de $\mathrm{Si}$ (silicato de $\mathrm{Ca}$, silicato de $\mathrm{Ca} \mathrm{e}$ $\mathrm{Mg}$ e termofosfato) foram mais eficientes que o calcário em disponibilizar Ca no solo, conforme sua maior reatividade e solubilidade no solo, concordando com resultados obtidos por Melo et al. (2003). Isso ocorreu, provavelmente, porque as fontes de $\mathrm{Si}$ apresentam uma reatividade no solo 6,78 vezes superior à do calcário (Alcarde \& Rodella, 2003). Korndörfer et al.(2001), no entanto, observaram um incremento de $68 \%$ de Ca fornecido pelo silicato até à profundidade de $40 \mathrm{~cm}$. Analisando, em profundidade, as colunas de lixiviação $(>30 \mathrm{~cm})$, percebeu-se que os teores de

Quadro 1. Caracterização química e textural da amostra de terra do Neossolo Quartzarênico órtico típico utilizada nos lisímetros antes da aplicação dos tratamentos

\begin{tabular}{|c|c|c|c|c|c|c|c|c|c|c|}
\hline $\mathrm{pH}\left(\mathrm{H}_{2} \mathrm{O}\right)$ & $\mathbf{C a}^{2+(1)}$ & $\mathbf{M g}^{2+(1)}$ & $\mathrm{Al}^{3+(1)}$ & $\mathbf{P}^{(2)}$ & $\mathbf{K}^{(2)}$ & $\mathbf{S}^{(3)}$ & $\mathrm{H}+\mathrm{Al}^{(4)}$ & $\mathbf{T}^{(5)}$ & $\mathbf{m}^{(7)}$ & $\mathbf{M O}^{(8)}$ \\
\hline $1: 2,5$ & - & $\mathrm{cmol}_{\mathrm{c}} \mathrm{dm}^{-3}$ & 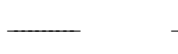 & \multicolumn{2}{|c|}{$-\mathrm{mg} \mathrm{dm}^{-3}-$} & 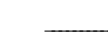 & $\mathrm{cmol}_{\mathrm{c}} \mathrm{dm}^{-3}$ & - & $-\%$ & $\mathrm{~g} \mathrm{~kg}^{-1}$ \\
\hline 4,4 & 0,2 & 0,1 & 1,00 & 5,6 & 19 & 0,35 & 4,85 & 5,20 & 71 & 15 \\
\hline $\mathrm{S}_{-} \mathrm{SO}_{4}(9)$ & $\mathbf{S i}^{(10)}$ & $\mathrm{Fe}^{(11)}$ & $\mathbf{M n}^{(11)}$ & & $\mathrm{Cu}^{(11)}$ & $\mathbf{Z n}^{(11)}$ & $\mathbf{B}^{(12)}$ & $\operatorname{Areia}^{(13)}$ & Silte ${ }^{(13)}$ & Argila(13) \\
\hline 5 & 3,3 & 185 & 6,1 & & 0,94 & 0,32 & 0,28 & 844 & 3 & 153 \\
\hline
\end{tabular}

Quadro 2. Caracterização dos corretivos e condicionadores utilizados no estudo de lixiviação (teores totais)

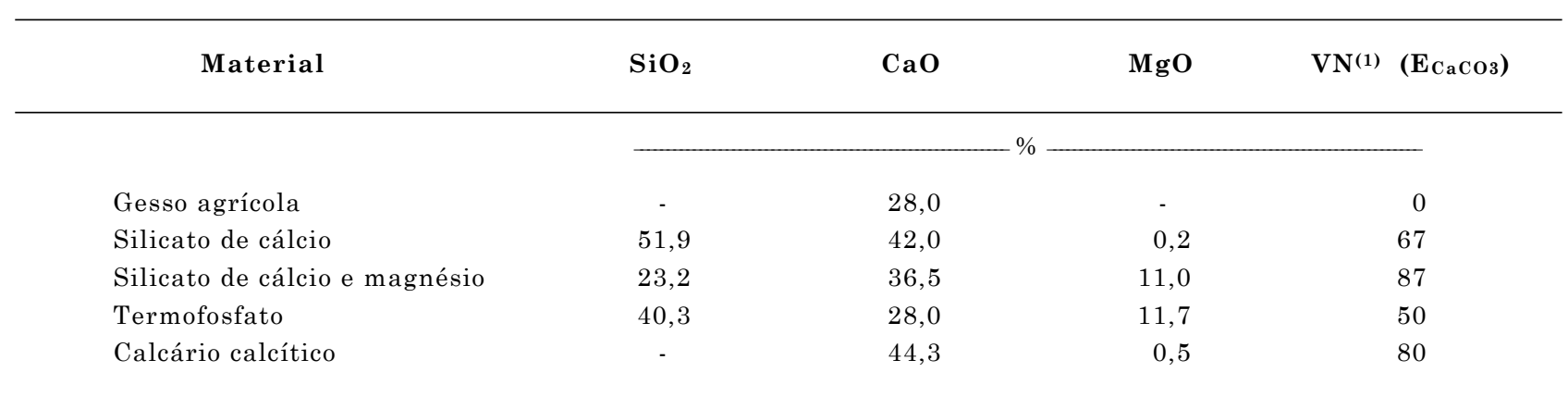

(1) Valor neutralizante relativo ao $\mathrm{CaCO}_{3}$. 
Quadro 3. Doses dos corretivos e condicionadores utilizados no estudo de lixiviação

\begin{tabular}{|c|c|c|c|}
\hline Material & Dose de Ca & Dose do produto & $\begin{array}{c}\text { Equivalente } \\
\mathrm{CaCO}_{3} \text { aplicado }\end{array}$ \\
\hline & + & $\mathrm{kg} \mathrm{ha}^{-1}$ & 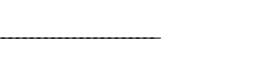 \\
\hline Gesso agrícola & $\begin{array}{r}500 \\
1.000\end{array}$ & $\begin{array}{l}2.500 \\
5.000\end{array}$ & $\begin{array}{l}0 \\
0\end{array}$ \\
\hline Wollastonita & $\begin{array}{r}500 \\
1.000\end{array}$ & $\begin{array}{l}1.165 \\
3.330\end{array}$ & $\begin{array}{r}781 \\
1.561\end{array}$ \\
\hline Silicato de cálcio e magnésio & $\begin{array}{r}500 \\
1.000\end{array}$ & $\begin{array}{l}1.915 \\
3.830\end{array}$ & $\begin{array}{l}1.666 \\
3.332\end{array}$ \\
\hline Termofosfato & $\begin{array}{r}500 \\
1.000\end{array}$ & $\begin{array}{l}2.500 \\
5.000\end{array}$ & $\begin{array}{l}1.250 \\
2.500\end{array}$ \\
\hline Calcário calcítico & $\begin{array}{r}500 \\
1.000\end{array}$ & $\begin{array}{l}1.580 \\
3.160\end{array}$ & $\begin{array}{l}1.264 \\
2.528\end{array}$ \\
\hline
\end{tabular}

Ca trocável foram baixos $\left(<0,4 \mathrm{cmol}_{\mathrm{c}} \mathrm{kg}^{-1}\right)$ e próximos da condição original do solo $\left(0,2 \mathrm{cmol}_{\mathrm{c}} \mathrm{kg}^{-1}\right)$. Embora o silicato seja mais solúvel, o Si apresentou outras interações com o solo, como a adsorção à superfície das partículas do solo.

O gesso, conforme esperado, disponibilizou Ca no solo até à subsuperfície dos lisímetros. A partir dos $30 \mathrm{~cm}$ de profundidade, o teor de $\mathrm{Ca}$ manteve-se superior ao dos outros produtos testados na dose $500 \mathrm{~kg} \mathrm{ha}^{-1}$ (Figura 1a), o que confirma sua mobilidade no perfil de solo e o efeito "condicionador" do solo (Alcarde 1992; Alcarde \& Rodella, 2003). Resultados semelhantes foram obtidos em trabalhos testados em parcelas de campo (Caires et al., 2003). Para a dose de $1.000 \mathrm{~kg} \mathrm{ha}^{-1}$ de gesso, não ocorreu diferença entre os materiais testados, o que não era esperado (Figura 1b). Isso pode ter ocorrido porque o aumento na concentração de Ca na solução do solo e o possível deslocamento de partículas de calcário no perfil do solo tornaram viável uma maior movimentação em profundidade dos materiais menos móveis, como o calcário e fontes de Si (Santos, 1999; Franchini et al., 2001; Amaral et al., 2004). Além disso, é importante mencionar que ensaios conduzidos em colunas de lixiviação podem apresentar um fluxo preferencial de água e compostos pelas paredes dos vasos, o que pode superestimar a movimentação de nutrientes no perfil, reduzindo as diferenças no deslocamento de nutrientes provenientes de fontes com solubilidade distinta, principalmente com a maior dose de Ca utilizada (1.000 kg ha-1).

Quanto aos teores de Mg nos anéis dos lisímetros (Figura 1c, d), o calcário, o gesso e o silicato de Ca Wollastonita (apenas 0,2\% de $\mathrm{MgO}$ ) foram pouco eficientes na disponibilização de $\mathrm{Mg}$ no solo pela ausência desse nutriente em sua composição, permanecendo com teores baixos $\left(\leq 0,1 \mathrm{cmol}_{\mathrm{c}} \mathrm{kg}^{-1}\right)$, próximos aos encontrados na condição original do solo $\left(0,1 \mathrm{cmol}_{\mathrm{c}} \mathrm{kg}^{-1}\right)$.

Dentre os materiais testados, o termofosfato e o silicato de Ca e Mg foram os produtos mais eficientes em disponibilizar $\mathrm{Mg}$ no solo na camada de 0-25 cm (Figura 1c,d), pela sua maior concentração de Mg em sua composição (Quadro 2) e o seu uso em doses elevadas (1.915 e $3.830 \mathrm{~kg} \mathrm{ha}^{-1}$ de silicato de Ca e Mg e 2.500 e $5.000 \mathrm{~kg} \mathrm{ha}^{-1}$ de termofosfato). O termofosfato foi a fonte mais eficiente na disponibilização de $\mathrm{Mg}$ no solo na camada de 0-30 cm, seguido do silicato de Ca e Mg (Figura 1c, d). Abaixo de $30 \mathrm{~cm}$, não ocorreu aumento na concentração de $\mathrm{Mg}$ entre as fontes de $\mathrm{Si}$ testadas, provavelmente em decorrência do curto período de incubação (40 dias).

Um dos objetivos do ensaio em lisímetros foi estudar a correção da acidez em profundidade. O silicato de $\mathrm{Ca}$ e $\mathrm{Mg}$ foi mais eficiente em aumentar o pH do solo na camada de 0-25 cm, quando foi utilizada a dose de $500 \mathrm{~kg} \mathrm{ha}^{-1}$ de Ca (Figura 1e), o que era esperado, pois foi a fonte que apresentou a maior dose de equivalente $\mathrm{CaCO}_{3}$ (Quadro 3). Esses resultados concordam, também, com aqueles obtidos em parcelas de campo (Korndörfer et al., 2001), em que silicatos de Ca e Mg propiciaram correção da acidez do solo na camada de 0-40 cm. O termofosfato apresentou-se mais eficiente que o calcário, uma vez que a aplicação de equivalente $\mathrm{CaCO}_{3}$ entre esses produtos foi semelhante. Embora a dose do termofosfato tenha sido inferior à do silicato de $\mathrm{Ca} \mathrm{e} \mathrm{Mg}$, os resultados de $\mathrm{pH}$ foram semelhantes, principalmente na dose de $1.000 \mathrm{~kg} \mathrm{ha}^{-1}$ de Ca. O silicato de Ca (Wollastonita), por sua vez, foi mais eficiente que o calcário na correção da acidez do solo na camada de $0-15 \mathrm{~cm}$. Considerando a quantidade equivalente de $\mathrm{CaCO}_{3}$ aplicada, a Wollastonita foi a fonte mais eficiente na correção da acidez por ser a menor dose aplicada. 


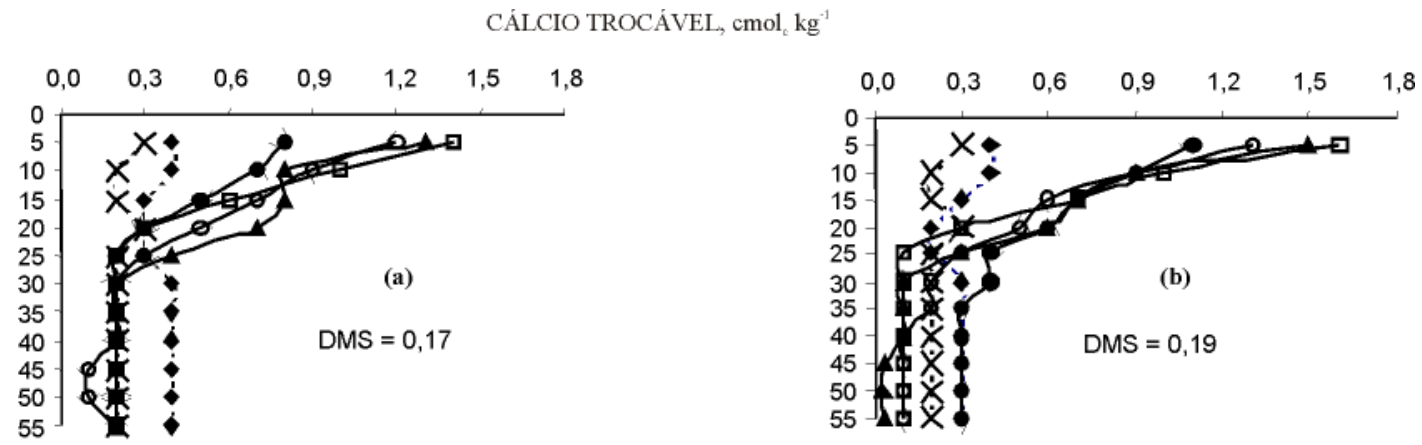

MAGNÉSIO TROCÁVEL, $\mathrm{cmol}_{\mathrm{c}} \mathrm{kg}$
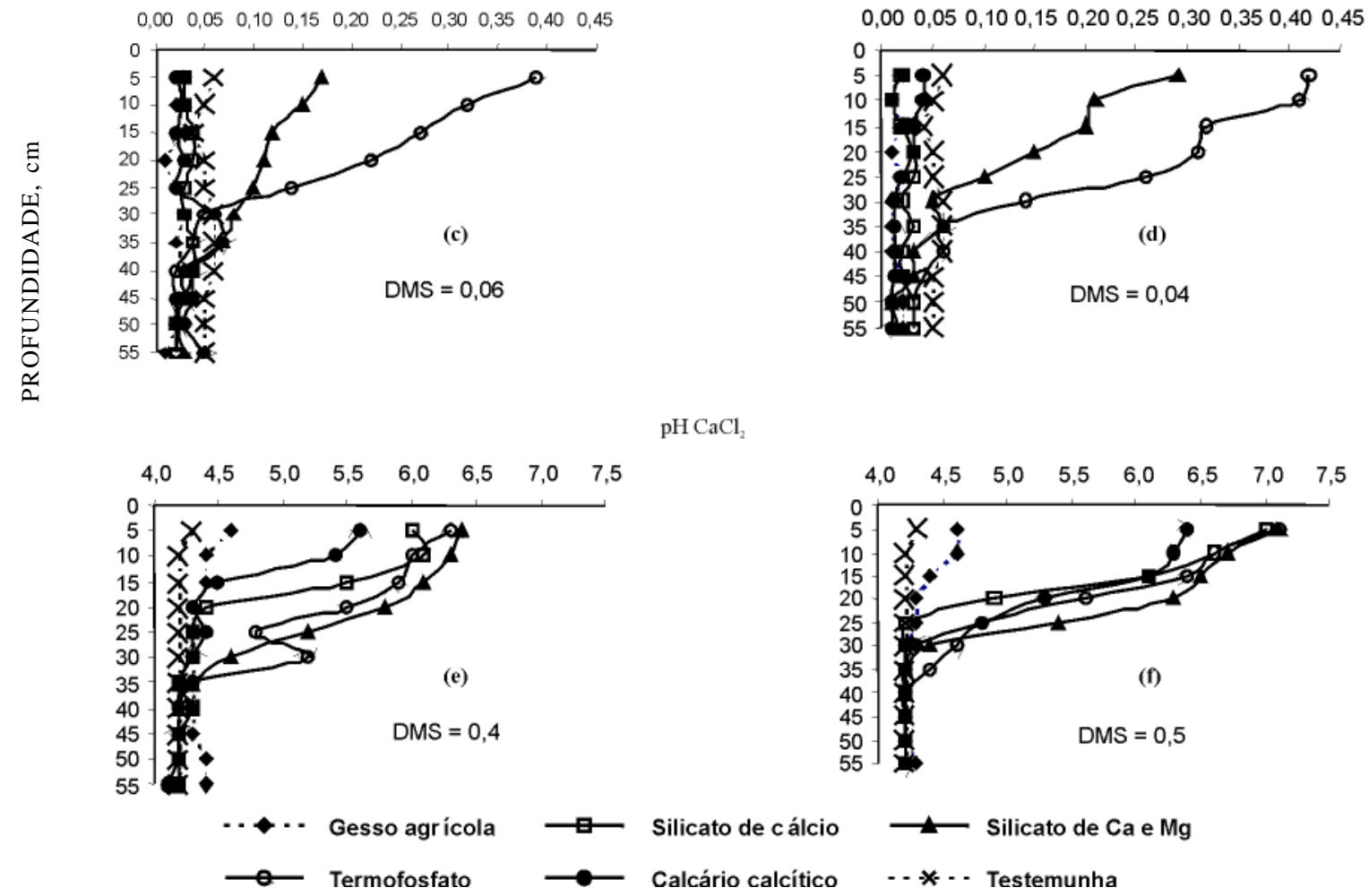

Figura 1. Dinâmica do cálcio (a, b), magnésio (c, d) $\mathrm{pH}-\mathrm{CaCl}_{2}(\mathrm{e}, \mathrm{f})$ em profundidade, considerando a aplicação de 500 (a, c, e) e $1.000 \mathrm{~kg} \mathrm{ha}^{-1}(\mathrm{~b}, \mathrm{~d}, \mathrm{f})$ de cálcio, na forma de corretivos e condicionadores de solo.

De forma geral, os silicatos foram mais eficientes na correção da acidez apesar das diferenças observadas na aplicação de equivalente $\mathrm{CaCO}_{3}$ decorrente do balanceamento do Ca. Faria (2000) constatou um aumento progressivo no $\mathrm{pH}$ do solo com aplicação de $6.000 \mathrm{~kg} \mathrm{ha}^{-1}$ de fontes de silicato, em que o $\mathrm{pH}$ aumentou, em média, de 4,2 para 4,8 em Neossolo Quartzarênico órtico típico, e de 4,6 para 5,1, em um Latossolo Vermelho distrófico típico.

A partir dos $15 \mathrm{~cm}$, não houve efeito corretivo das fontes testadas (Figuras 1e, f). Mesmo com poder de neutralização e granulometria similares entre os tratamentos empregados no experimento, o maior efeito corretivo em subsuperfície dos silicatos pode ter ocorrido em razão de sua maior solubilidade (6,78 vezes superior ao do calcário - Alcarde \& Rodella, 2003). Embora o calcário seja considerado um eficiente corretivo de acidez, sua ação neutralizante não ultrapassa o $\mathrm{pH} \mathrm{em} \mathrm{CaCl}_{2}$ de 6,5 , graças à redução de sua solubilidade nesse nível de $\mathrm{pH}$, sendo menor que a dos silicatos, visto que sua base $\left(\mathrm{CO}_{3}{ }^{2-}\right)$ é mais fraca $\left(\mathrm{Kb}_{1}=2,2 \times 10^{-4}\right)$ que a base dos silicatos $\left(\mathrm{SiO}_{3}{ }^{2-}\right.$ $\left(\mathrm{Kb}_{1}=1,6 \times 10^{-3}\right)$, ou seja, apresenta uma liberação mais lenta de hidroxilas para o meio (Alcarde \& Rodella, 2003). O gesso, como esperado, não foi eficaz na correção da acidez do solo nas colunas de lixiviação (Figuras 1e, f) por ser um condicionador de solo e não um corretivo da acidez do solo (Alcarde, 1992; Alcarde \& Rodella, 2003). 
Com relação aos teores de Si no solo, separou-se a camada superficial de terra dos lisímetros $(0-5 \mathrm{~cm})$ das demais camadas $(5-55 \mathrm{~cm})$, visto que as fontes silicatadas reagiram e disponibilizaram muito Si no solo (até $1.218,5 \mathrm{mg} \mathrm{kg}^{-1}$ ) na camada superficial, o que dificultaria a comparação, em profundidade, das fontes estudadas. Na camada de $0-5 \mathrm{~cm}$, as fontes de Si (silicato de $\mathrm{Ca}$ e $\mathrm{Mg}$, silicato de $\mathrm{Ca}$ - Wollastonita e termofosfato) apresentaram valores altos, demonstrando a alta reatividade dos produtos (Figura 2). O termofosfato foi a fonte que apresentou maior liberação de Si para o solo, ao contrário do esperado, pois a Wollastonita (padrão) apresentou $51,9 \%$ de $\mathrm{SiO}_{2}$. Isso pode ser atribuído às altas doses (2500 e $5000 \mathrm{~kg} \mathrm{ha}^{-1}$ ) de termofosfato aplicadas (Quadro 3). Além disso, o extrator ácido acético pode ser capaz de extrair formas de Si não disponíveis às plantas, tais como: formas polimerizadas (ácido polisilícico) ou mesmo Si na fase sólida do solo (argilominerais), superestimando os valores de Si em solução (Braga, 2004; Korndörfer et al., 2004a).

Quanto à dinâmica das fontes de $\mathrm{Si}$ em profundidade (camada de $5-55 \mathrm{~cm}$ ), o calcário e o gesso apresentaram uma concentração de Si em todo perfil dos lisímetros muito próximo do tratamentotestemunha (Figura 3a, b) por não conterem Si em sua composição. Nos primeiros $20 \mathrm{~cm}$, o termofosfato, o silicato de Ca e o silicato de Ca e Mg apresentaram aumento na disponibilidade de Si (Figura 3a, b). O aumento na concentração de $\mathrm{Si}$ no solo pode ser benéfico para o crescimento e desenvolvimento das plantas, uma vez que são conhecidos os seus benefícios para o aumento da tolerância ao estresse hídrico, aumento da capacidade fotossintética, diminuição do acamamento, redução da transpiração e aumento da resistência ao ataque de pragas e doenças (Epstein, 1994; Korndörfer et al.,1999; Korndörfer et al., 2004a, b). O calcário e o gesso não diferiram da testemunha pela ausência de Si em sua composição (Quadro 2).

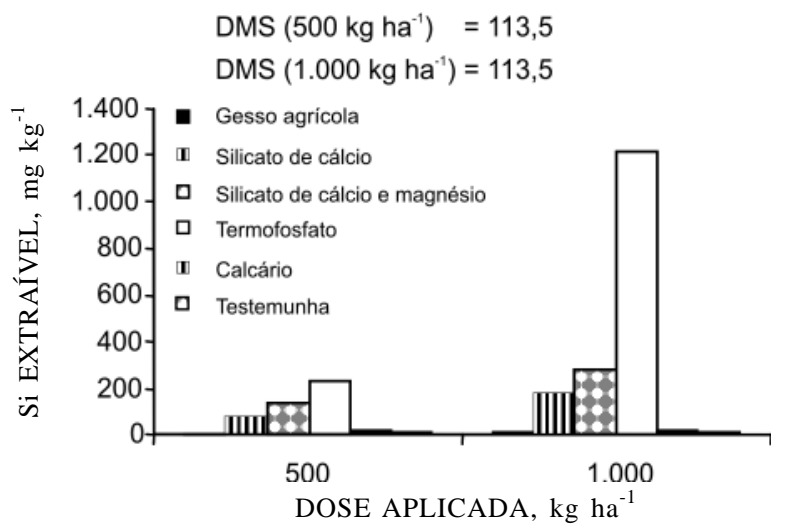

Figura 2. Concentração de silício (extrator ácido acético $0,5 \mathrm{~mol} \mathrm{~L}^{-1}$ ) nos lisímetros (camada de 0-5 cm) preenchidos com terra de um Neossolo Quartzarênico órtico típico.

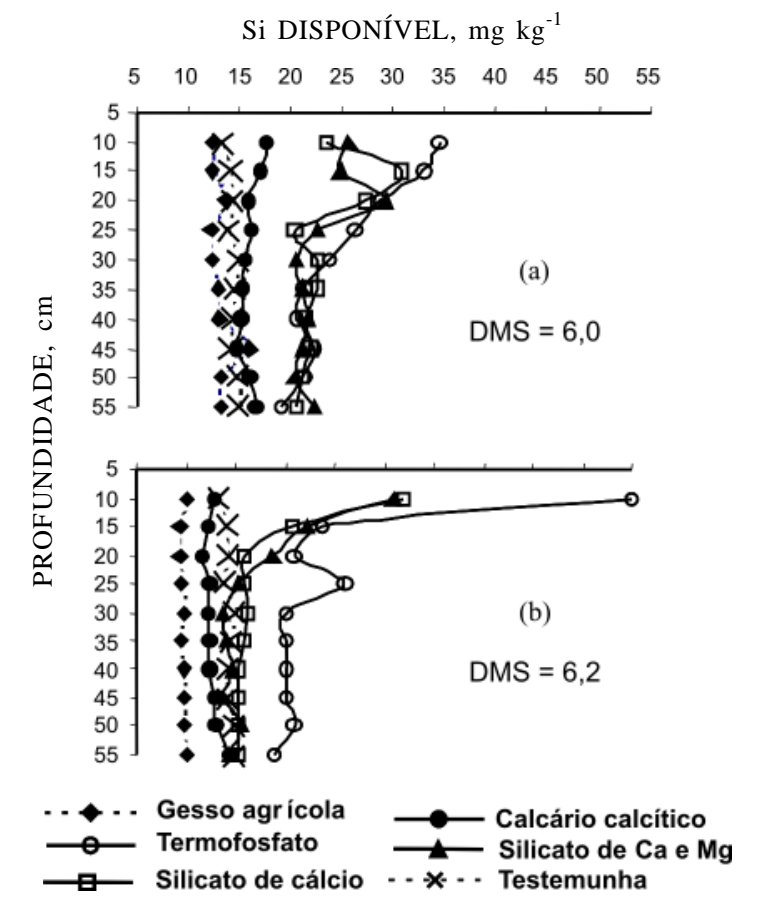

Figura 3. Dinâmica do silício em profundidade, considerando a aplicação de 500 (a) e $1.000 \mathrm{~kg} \mathrm{ha}^{-1}$ (b) de cálcio, na forma de corretivos e condicionadores de solo.

\section{CONCLUSÕES}

1. O gesso aumentou a disponibilidade de $\mathrm{Ca}$ trocável em todas as profundidades das colunas de lixiviação.

2. As fontes de $\mathrm{Si}$ aumentaram os teores de $\mathrm{Ca}$ trocável com maior eficiência que o calcário na camada superficial $(0-5 \mathrm{~cm})$.

3. Os silicatos estudados (silicato de $\mathrm{Ca}$, silicato de Ca e Mg e termofosfato) promoveram a correção da acidez do solo com maior eficiência que o calcário, até à camada de $0-15 \mathrm{~cm}$ de profundidade na dose de $500 \mathrm{~kg} \mathrm{ha}^{-1} \mathrm{de} \mathrm{Ca}$.

4. A aplicação de silicato de $\mathrm{Ca}$ e $\mathrm{Mg}$ e de termofosfato aumentou a concentração de $\mathrm{Mg}$ no solo até à profundidade de $25 \mathrm{~cm}$.

5. O Si foi carreado até às camadas mais profundas dos lisímetros $(55 \mathrm{~cm})$, independentemente da fonte de Si utilizada.

\section{AGRADECIMENTOS}

Os autores agradecem ao apoio financeiro da iniciativa privada (Recmix do Brasil e Fertilizantes Mitsui) e do CNPq, sem o qual não seria possível a realização deste trabalho. 


\section{LITERATURA CITADA}

ALCARDE, J.A. \& RODELLA, A.A. Qualidade e legislação de fertilizantes e corretivos. In: CURI, N.; MARQUES, J.J.; GUILHERME, L.R.G.; LIMA, J.M.; LOPES, A. S. \& ALVARES V., V.H., eds. Tópicos em Ciência do Solo. Viçosa, Sociedade brasileira de Ciência do Solo, 2003. p.291-334.

ALCARDE, J.C. Corretivos da acidez dos solos: Características e interpretações técnicas. 2 ed. São Paulo, ANDA, 1992. 26p. (Boletim Técnico, 6)

AMARAL, A.S. \& ANGHINONI, I. Alteração de parâmetros químicos do solo pela reaplicação superficial de calcário no sistema plantio direto. Pesq. Agropec. Bras., 36:695$702,2001$.

AMARAL, A.S.; ANGHINONI, I. \& DESCHAMPS, F.C. Resíduos de plantas de cobertura e mobilidade dos produtos da dissolução do calcário aplicado na superfície do solo. R. Bras. Ci. Solo, 28:115-123, 2004.

ANDO, J.; OWA, N. \& ASANO, M. Studies on structure, solubility and agronomic response of industrial slag. Effects of aluminium on solubility and agronomic response of slags. Jap. J. Soil Sci. Plant Nutr., 59:27-32, 1998.

BRAGA, A.M.C. Eficiência agronômica de fertilizantes contendo silício (serpentinito) e potássio $(\mathrm{KCl})$ na adubação do arroz inundado e sorgo. Uberlândia, Universidade Federal de Uberlândia, 2004. 83p. (Tese de Mestrado)

CAIRES, E.F.; BLUM, G. \& BARTH, F.J. Alterações química do solo e resposta da soja ao calcário e gesso aplicados na implantação do sistema plantio direto. R. Bras. Ci. Solo, 27:275-286, 2003.

COELHO, P.E. Da escória ao vidro. R. Limp. Publ., 49:36-45, 1998.

DALTO, G. Manejo de silicato e calcário em soja cultivada sobre palhada de cana-de-açúcar. Uberlândia, Universidade Federal de Uberlândia, 2003. 102p. (Tese de Mestrado)

EMPRESA BRASILEIRA DE PESQUISA AGROPECUÁRIA EMBRAPA. Centro Nacional de Pesquisas de Solos. Sistema brasileiro de classificação de solos. Brasília, Embrapa Produção de Informação, 1999a. 412p.

EMPRESA BRASILEIRA DE PESQUISA AGROPECUÁRIA EMBRAPA. Centro Nacional de Pesquisas de Solos. Manual de análises químicas de solos, plantas e fertilizantes. Brasília, Embrapa Comunicação para Transferência de Tecnologia, 1999b. 370p.

EMPRESA BRASILEIRA DE PESQUISA AGROPECUÁRIA EMBRAPA. Centro Nacional de Pesquisas de Solos. Manual de métodos de análise de solo. 2.ed. Rio de Janeiro, 1997. 212p.

EPSTEIN, E. The anomaly of silicon in plant biology. Proc. Nat. Acad. Sci. USA., 91:11-17, 1994.

FARIA, R.J. Influência do silicato de cálcio na tolerância do arroz de sequeiro ao déficit hídrico do solo. Lavras, Universidade Federal de Lavras, 2000. 47p. (Tese de Mestrado)
FRANCHINI, J.C.L.; MALAVOLTA, E.; MIYAZAWA, M. \&... Rapid transformations of plant water-soluble organic compounds in relation to cation mobilization in an acid Oxsiol. Plant Soil, 231:55-63, 2001.

FRANCHINI. J.C.L.; MIYAZAWA, M.; PAVAN, M.A. \& MALAVOLTA, E. Dinâmica de íons em solo ácido lixiviado com extratos de resíduos de adubos verdes e soluções puras de ácidos orgânicos. Pesq. Agropec. Bras., 34:22672276, 1999.

GOMES, M.F.A. Influência de ferro e alumínio amorfos do solo na reatividade de quatro corretivos de acidez. Ceres, 43:444-453, 1996

KORNDÖRFER, G.H.; ARANTES, V.A.; CORRÊA, G.F. \& SNYDER, G.H. Efeito do silicato de cálcio no teor de silício no solo e na produção de grãos de arroz de sequeiro. R. Bras. Ci. Solo, 23:635-641, 1999.

KORNDÖRFER, G.H. Fósforo na cultura da cana de açúcar. In: YAMADA, T. \& ABDALLA, S.R.S., eds. Fósforo na agricultura brasileira. Piracicaba, Associação Brasileira para Pesquisa da Potassa e do Fosfato, 2004. p.290-306.

KORNDÖRFER, C.M.; KORNDÖRFER, G.H.; LANA, R.M.Q.; CORRÊA, G.F. \& JUNQUEIRA NETO, AA. Correção da acidez do solo com silcato de cálcio e o papel do silício na recuperação de pastagem degradada de Brachiaria decumbens. In: CONGRESSO BRASILEIRO DE CIÊNCIA DO SOLO, 28., Londrina, 2001. Anais. Viçosa, MG, Sociedade Brasileira de Ciência do Solo, 2001. p.144144.

KORNDÖRFER, G.H. \& GASCHO, G.J. Avaliação de fontes de silício para o arroz. In: CONGRESSO BRASILEIRO DE ARROZ IRRIGADO, 1., Pelotas, 1999. Anais. Pelotas, Embrapa, 1999. p.313-316.

KORNDÖRFER, G. H.; PEREIRA. H.S. \& NOLLA. A. Análise de silício: solo, planta e fertilizante. Uberlândia, GPSi/ ICIAG/UFU, 2004a. 34p. (Boletim Técnico, 2)

KORNDÖRFER, G.H.; PEREIRA, H.S. \& CAMARGO, M.S. Silicatos de cálcio e magnésio na agricultura. Uberlândia, GPSi/ICIAG/UFU, 2004b. 28p. (Boletim Técnico, 1)

LOUZADA, P.T.C. Eficiência de uma escória de siderurgia como corretivo e fertilizante do solo. Viçosa, MG, Universidade Federal de Viçosa, 1987. 52p. (Tese de Mestrado)

MELO, S.P.; KORNDÖRFER, G.H.; KORNDÖRFER, C.M.; LANA, R.M.Q. \& SANTANA, D.G. Silicon accumulation and water deficit tolerance in brachiaria grasses. Sci. agric., 60:755-759.

NOLLA, A. Correção da acidez do solo com silicatos. In: SIMPÓSIO SOBRE SILÍCIO NA AGRICULTURA. 3., Uberlândia, 2004. Palestras. Uberlândia, GPSi/ICIAG/ UFU, 2004. CD-ROM

NOVAIS, R.F.; BARROS, N.F.; LEITE, F.P.; TEIXEIRA, J.L. \& LEAL, P.G.L.. Eficiência agronômica de escórias da Siderúrgica Pains. Viçosa, MG, Universidade Federal de Viçosa, 1993. 110p.

PAVAN, M.A. Mobilização orgânica do calcário no solo através de adubo verde. In: FUNDAÇÃO CARGILL, ed. Plantio direto: atualização tecnológica. Castro, Fundação Cargill/ Fundação ABC, 1999. p.45-52. 
PAVAN, M.A. Movimentação de calcário no solo através de técnicas de manejo da cobertura vegetal em pomares de macieira. R. Bras. Frutic., 16:86-91, 1994.

PEREIRA, J.E. Solubilidade de alguns calcários e escórias de alto forno. Viçosa, MG, Universidade Federal de Viçosa, 1978. 84p. (Tese de Mestrado)

PRADO, R.M.; FERNANDES, F.M. \& NATALE, W. Uso agrícola da escória de siderurgia no Brasil - Estudos na cultura da cana-de-açúcar. Jaboticabal, Funep, 2001. 68p.

RHEINHEIMER, D.S.; SANTOS, E.J.S.; KAMINSKI, J.; BORTOLUZZI, E.E. \& GATIBONI, L.C. Alterações de atributos do solo pela calagem superficial e incorporada a partir de pastagem natural. R. Bras. Ci. Solo, 24:795-805, 2000.

SÁ, J.C.M. Manejo da Fertilidade do solo no plantio direto. Castro, Fundação ABC, 1993. 94p.
SANTOS, J.C.F. Mobilização de cálcio e alumínio em solos ácidos por compostos orgânicos hidrossolúveis de resíduos vegetais. Piracicaba, Universidade de São Paulo, 1999. 72p. (Tese de Doutorado)

SOUSA, D.M. \& LOBATO, E. Cerrado: Correção do solo e adubação. 2.ed. Brasília, Embrapa Informação Tecnológica, 2004. 416p.

VELOSO, C.A.C.; BORGES, A.L.; MUNIZ, A.S. \& VIEGAS, I.J.M. Efeitos de diferentes materiais no $\mathrm{pH}$ do solo. Sci. Agric., 49:123-128, 1992.

VITTI, G.C.; WIT, A. \& FERNANDES, B.E.P. Eficiência agronômica dos termofosfatos e fosfatos alternativos. In: YAMADA, T. \& ABDALLA, S.R.S., eds. Fósforo na agricultura brasileira. Piracicaba, Associação Brasileira para Pesquisa da Potassa e do Fosfato, 2004. p.688-726. 